\title{
Assessing the subjective and physiological effects of intranasally administered crushed extended-release morphine formulations with and without a sequestered naltrexone core in recreational opioid users
}

\author{
Beatrice Setnik $\mathrm{PhD}^{1}$, Veeraindar Goli $\mathrm{MD}^{1,2}$, Naama Levy-Cooperman $\mathrm{PhD}^{3}$, Catherine Mills $\mathrm{MSc}^{3}$, \\ Megan Shram $\mathrm{PhD}^{3,4}$, Ira Smith $\mathrm{MD}^{3}$
}

\begin{abstract}
B Setnik, V Goli, N Levy-Cooperman, C Mills, M Shram, I Smith. Assessing the subjective and physiological effects of intranasally administered crushed extended-release morphine formulations with and without a sequestered naltrexone core in recreational opioid users. Pain Res Manag 2013;18(4):e55-e62.
\end{abstract}

OBJECTIVE: To evaluate the pharmacodynamic (PD) effects of morphine sulfate and naltrexone hydrochloride extended-release (MSN) capsules compared with controlled-release morphine sulfate (MS) and placebo when crushed and administered intranasally.

METHODS: The present study was a randomized, double-blinded, placebo-controlled, single-dose $(30 \mathrm{mg})$, three-way crossover study in healthy, nondependent recreational opioid users. PD measures included assessment of subjective drug effects using visual analogue scales (VAS) ranging from 0 to 100 and assessments of pupil diameter. Blood samples were collected for pharmacokinetic analyses.

RESULTS: Both MS and MSN showed significantly higher PD values compared with placebo. MSN showed significantly lower scores for drug liking and high VAS scores on both mean peak effect $\left(\mathrm{E}_{\max }\right)$ (69.6 and 55.2 , respectively) and in area under the effect curve over $2 \mathrm{~h}$ (86.3 and 66.7, respectively) following dosing compared with $\mathrm{MS}\left(\mathrm{E}_{\max } 87.6\right.$ and 86.6, respectively; area under the curve over 2 h 120.6 and 132.9 , respectively; $\mathrm{P}<0.001$ ). MSN showed significantly lower $\mathrm{E}_{\max }$ for all other positive subjective effects (good drug effects, overall drug liking, and take drug again VAS scores) compared with MS $(\mathrm{P}<0.001)$. Peak minimum pupil diameter was significantly larger for MSN than MS ( $\mathrm{P}=0.002)$. Mean peak plasma concentration $\left(\mathrm{C}_{\max }\right)$ and median time to $\mathrm{C}_{\max }$ for morphine following administration of MSN and MS were similar $(27.3 \mathrm{ng} / \mathrm{mL}$ and $0.57 \mathrm{~h}$ versus $27.7 \mathrm{ng} / \mathrm{mL}$ and $0.6 \mathrm{~h}$, respectively). Naltrexone mean $\mathrm{C}_{\max }$ was $1497 \mathrm{pg} / \mathrm{mL}$ after MSN and median time to $\mathrm{C}_{\max }$ was $0.55 \mathrm{~h}$.

CONCLUSIONS: When crushed and administered intranasally, MSN was associated with significantly lower ratings of drug liking and other positive subjective effects compared with MS.

Key Words: Abuse potential; Drug liking; Intranasal administration; Morphine; Naltrexone; Pharmacodynamic; Pharmacokinetic
L'évaluation des effets subjectifs et physiologiques de formulations de morphine à libération prolongée écrasée, administrées par voie nasale avec et sans naltrexone inhibée chez des consommateurs d'opioïdes à des fins récréatives

OBJECTIF : Évaluer les effets pharmacodynamiques (PD) de capsules de sulfate de morphine (SM) et d'hydrochlorure de naltrexone à libération prolongée (NSM) par rapport au SM à libération contrôlée et à un placebo lorsqu'ils sont écrasés et administrés par voie intranasale.

MÉTHODOLOGIE : La présente étude transversale aléatoire à double insu, contrôlée contre placebo, à dose unique $(30 \mathrm{mg})$ et à trois voies a été effectuée auprès de consommateurs d'opioïdes à usage récréatif en santé et non dépendants. Les mesures PD incluaient une évaluation des effets subjectifs de la drogue au moyen d'échelles analogiques visuelles (ÉAV) de 0 à 100 et des évaluations de la dimension des pupilles. Des échantillons de sang ont été prélevés en vue des analyses pharmacocinétiques.

RÉSULTATS : Tant le SM que le NSM présentaient des valeurs PD considérablement plus élevées que le placebo. Le NSM présentait des résultats considérablement moins élevés d'appréciation de la drogue et des résultats élevés à l'ÉAV, à la fois pour l'effet de pointe moyen $\left(\mathrm{E}_{\max }\right)(69,6$ et 55,2, respectivement) et pour la zone sous la courbe deux heures $(86,3$ et 66,7, respectivement) après l'administration de la dose que le $\mathrm{SM}\left(\mathrm{E}_{\max } 87,6\right.$ et 86,6 , respectivement; zone sous la courbe au bout de deux heures de 120,6 et $132,9$, respectivement; $\mathrm{P}<0,001)$. Le NSM présentait un $\mathrm{E}_{\max }$ considérablement plus faible à l'égard de tous les autres effets subjectifs positifs (résultats de l'ÉAV quant aux effets agréables, à l'appréciation globale et à la prise subséquente de la drogue) que le $\mathrm{SM}(\mathrm{P}<0,001)$. Le diamètre minimal de pointe des pupilles était considérablement plus gros après la prise de NSM que de SM $(\mathrm{P}=0,002)$. La concentration moyenne de plasma de pointe $\left(\mathrm{C}_{\max }\right)$ et le délai médian pour atteindre la $\mathrm{C}_{\max }$ de morphine après l'administration de NSM et de SM étaient similaires $(27,3 \mathrm{ng} / \mathrm{mL}$ et de 0,57 heure par rapport à $27,7 \mathrm{ng} / \mathrm{mL}$ et de 0,6 heure, respectivement). La $\mathrm{C}_{\text {max }}$ moyenne de naltrexone était de $1497 \mathrm{pg} / \mathrm{mL}$ après la prise de NSM, et le délai médian pour parvenir à la $\mathrm{C}_{\max }$, de 0,55 heure.

CONCLUSIONS : Lorsqu'il était écrasé et administré par voie intranasale, le NSM s'associait à des taux beaucoup plus faibles d'appréciation de la drogue et d'autres effets subjectifs positifs que le SM.

to various means of tampering to snort or inject tablets (4). The most prevalent route of administration for opioid abuse is oral ingestion, followed by snorting and injection (5). According to the National Addictions Vigilance Intervention and Prevention Program, morphine is most commonly abused via the intravenous route, followed by oral and intranasal routes (6).

The overdose death rate in the United States related to prescription opioids increased by almost fourfold from 1999 to 2009 (1.54 deaths per 100,000 person-years to 6.05 deaths per 100,000 person-years) (7). The estimated number of emergency department visits involving pain management, however, there is growing concern regarding poten there is growing concern regarding potenlion individuals in the United States $\geq 12$ years of age reported nonmedical use of a prescription pain medication within the past month, and approximately 2.0 million people first initiated nonmedical use of prescription pain medication within the past year (3).

To attain more rapid drug effects, nonmedical users of opioids often begin consuming excessive numbers of intact tablets and may progress
${ }^{1}$ Pfizer Inc, Cary; ${ }^{2}$ Duke University Medical Center, Durham, North Carolina, USA; ${ }^{3}$ INC Research; ${ }^{4}$ Department of Pharmacology and

Toxicology, University of Toronto, Toronto, Ontario

Correspondence: Dr Beatrice Setnik, Pfizer Inc, 4000 Centre Green Way, Suite 260, Cary, North Carolina 27513, USA.

Telephone 919-653-7071, fax 919-653-7022, e-mail beatrice.setnik@pfizer.com 
nonmedical use of narcotic pain relievers increased $111 \%$, from 144,644 in 2004 to 305,885 in 2008 (8). In an effort to provide appropriate pain management while reducing potential for abuse and misuse, new opioid formulations have been developed to deter common methods of tampering $(9,10)$.

An extended-release (ER) formulation of morphine sulfate surrounding an inner core of sequestered naltrexone (MSN) (EMBEDA ER, Pfizer Inc, USA), with demonstrated efficacy in treating chronic pain $(11,12)$, is designed to deter common methods of tampering associated with opioid abuse. When taken as directed, morphine is released, exerting its therapeutic effect, and naltrexone is largely sequestered and does not impart observable clinical effects (12). If tampering occurs by chewing or crushing MSN, the sequestered naltrexone is released and binds competitively to the opioid receptors, which reduces the pharmacological effects of the released morphine (13). A clinical study in healthy volunteers examining the relative bioavailability of crushed MSN following oral administration determined that the bioavailability of naltrexone and its metabolite $6 \beta$-naltrexol from crushed MSN was bioequivalent to orally administered naltrexone hydrochloride solution (14). In contrast, when intact MSN capsules were administered, concentrations of naltrexone and $6 \beta$-naltrexol were below the limit of quantification (14).

As outlined in the Food and Drug Association draft guidance, the primary measure for evaluating the abuse potential of a potentially abuse-deterrent formulation is the visual analogue scale (VAS) for drug liking because it correlates most directly with potential for abuse; other recommended measures include high, overall drug liking, and take the drug again (15). Drug liking and other measures of the subjective effects of MSN have been examined previously in nondependent recreational opioid users when administered via the intravenous or oral routes of administration $(13,16)$. One study showed that self-reports of high, euphoria and drug-liking effects were greater when morphine was taken intravenously alone than when it was coadministered with naltrexone as a clinical simulation of intravenous abuse of crushed MSN (16). Another study showed that recipients of orally administered intact or crushed MSN reported significantly less euphoria, drug liking and other subjective effects compared with immediate-release morphine (13). A recent study demonstrated that orally administered crushed MSN was associated with lower subjective drug effects, including drug liking and high compared with crushed, controlled-release morphine sulfate (MS) (17).

To date, the pharmacodynamic (PD) effects, including drug liking and high, of crushed MSN administered intranasally have not been evaluated and have not been compared with MS. In fact, to the best of our knowledge, the present study is the first report on these effects of morphine following intranasal administration. The present study was designed to evaluate the PD effects of MSN tablets compared with MS tablets and placebo when crushed and administered intranasally to nondependent recreational opioid users. The pharmacokinetics (PK), safety and tolerability of crushed MSN were also evaluated.

\section{Study population}

\section{METHODS}

Eligible participants included healthy male or female recreational opioid users, 18 to 55 years of age, with a body mass index of $18 \mathrm{~kg} / \mathrm{m}^{2}$ to $33 \mathrm{~kg} / \mathrm{m}^{2}$ and weight $\geq 50 \mathrm{~kg}$. Participants were to have used opioids for nontherapeutic purposes on $\geq 10$ occasions within the past year and at least once in the 12 weeks before the screening visit, but were not dependent on opioids based on Diagnostic and Statistical Manual of Mental Disorders-Fourth Edition (DSM IV)-Text Revision criteria (18); this was confirmed through a naloxone challenge. Participants had to be experienced with intranasal drug administration, defined as self-reported intranasal use on at least three occasions within the past year before screening. Female participants could not be pregnant or lactating and, if they were of childbearing age, had to have a confirmed negative pregnancy test at each visit. Participants who were diagnosed with substance and/or alcohol dependence (excluding caffeine and nicotine) based on the DSM-IV-Text Revision criteria, those positive for hepatitis $\mathrm{B}$ or $\mathrm{C}$ virus or HIV, those who had any condition in which an opioid is contraindicated (eg, significant respiratory depression, acute or severe bronchial asthma or hypercarbia, suspected of having paralytic ileus) or had a history or a current pulmonary disease were excluded. Participants who had a history or a current clinically significant medical condition were also excluded. Participants testing positive for tetrahydrocannabinol at screening (study visit 1) were included in the study if their tetrahydrocannabinol levels remained the same or decreased on testing at visit 2. Participants with a positive urine drug screen for opioids at study visit 1 were eligible if they tested negative at study visit 2 . Participants had to abstain from alcohol for $48 \mathrm{~h}$ before each study visit. To confirm eligibility to continue in the study, a urine drug screen was conducted before each study visit, and an alcohol breath test was conducted before each dosing.

\section{Study design}

The present study was a single-dose, randomized, double-blinded, placebo-controlled, three-way crossover study (ALO-01-10-4004; ClinicalTrials.gov NCT01595867). The study was conducted at Kendle Early Stage, Toronto, Ontario, from August 31, 2010 to January 6, 2011. The protocol and informed consent form were reviewed and approved by an institutional review board (Institutional Review Board Services, Aurora, Ontario). The present study was conducted in accordance with the International Conference on Harmonization Good Clinical Practice Guidelines and with the ethical principles described in the current revision of the Declaration of Helsinki. Additionally, all local regulatory requirements were followed and all participants provided written informed consent before entering the study.

After the screening visit (visit 1), all eligible participants underwent a naloxone challenge test (visit 2; day 0) to ensure that they were not dependent on opioids. During the naloxone challenge, all participants received an intravenous $0.2 \mathrm{mg}$ naloxone $\mathrm{HCl}$ bolus, followed by an assessment for signs of opioid withdrawal using the Clinical Opiate Withdrawal Scale. If no signs of withdrawal were present within $30 \mathrm{~s}$ (Clinical Opiate Withdrawal Scale score $<5$ ), an additional naloxone $0.6 \mathrm{mg}$ bolus dose was administered and the participants were observed for signs and symptoms of withdrawal for $5 \mathrm{~min}$. Only participants displaying no signs of withdrawal were eligible to continue in the study.

The study consisted of three phases: dose selection, drug discrimination and treatment. The dose selection phase was conducted to identify an appropriate dose of MS that could safely produce distinguishable effects from placebo on PD measures after intranasal administration. The purpose of the drug discrimination phase was to identify participants who were able to distinguish between intranasally administered MS and placebo on select subjective drug measures, demonstrated an acceptable placebo response, tolerated study treatments (based on available safety data) and followed study procedures.

During the dose selection phase (visit 2a; days 1 to 3 ), which required a stay in the study centre of up to three nights, crushed MS (30 mg) and placebo were administered intranasally in a doubleblinded crossover manner to the first cohort of four eligible participants; if the $30 \mathrm{mg}$ dose was deemed insufficient, the dose was escalated to $60 \mathrm{mg}$ and then $90 \mathrm{mg}$ in up to two cohorts of four new participants each. Determination of an appropriate dose was based on a maximum (peak) score $\left(E_{\max }\right)$ difference of $\geq 15$ points compared with placebo on the bipolar VAS (scale ranging from 0 to 100) for drug liking, and an appropriate response on other positive subjective measures (good drug effects, take drug again and overall drug liking) compared with placebo. The response to MS had to be in the appropriate direction (ie, toward increased drug liking, high), had to occur in at least two of the four participants and had to be absent of clinically significant safety/tolerability concerns. Subjects who did not participate in the dose selection phase underwent screening and naloxone 
challenge procedures to determine eligibility before entering the drug discrimination phase.

In the drug discrimination phase (visit $2 \mathrm{~b}$; days 1 to 3 ), which required a stay in the study centre of up to three nights, participants received the selected dose of crushed MS (ie, $30 \mathrm{mg}$ ) and placebo intranasally; dosing was separated by approximately $24 \mathrm{~h}$. After each dose, PD and safety measures were recorded up to $8 \mathrm{~h}$ postdose. Participants who adequately discriminated between the two treatments were eligible to continue; adequate discrimination was defined as $\mathrm{E}_{\max }$ scores greater than placebo on VAS drug liking ( $\geq 15$ points) and on unipolar VAS high ( $\geq 30$ points).

In the treatment phase (treatment periods 1 to 3 ; visits 3 to 5 with two-night confined stay per visit), participants received each of the following three treatments (one per treatment period) in random order according to one of six treatment sequences based on two Williams squares design: placebo, crushed MSN (30 mg) or crushed MS tablet $(30 \mathrm{mg})$. After each treatment, PD, PK and safety assessments were conducted for up to $24 \mathrm{~h}$ postdose. Fasting was required for at least $8 \mathrm{~h}$ before each dosing and approximately $2 \mathrm{~h}$ after dosing. Each drug administration was separated by approximately $24 \mathrm{~h}$ during the drug discrimination phase and by four to 14 days during the treatment phase. Final safety assessments were conducted at a follow-up visit (visit 6) three to 14 days following the last study drug administration or time of early withdrawal.

\section{Drug administration}

MS (MS Contin sustained-release tablets; Purdue Pharma Inc, USA) and placebo (lactose $100 \mathrm{mg}$ tablets; Odan Laboratories Ltd, Canada) were prepared for intranasal administration by manually crushing the tablets using a mortar and pestle for a minimum of $2 \mathrm{~min}$ to obtain a fine homogeneous powder. Placebo was weighed to correspond to either the theoretical fill weights or average tablet weight of the drug products under evaluation. MSN tablets contained $30 \mathrm{mg}$ morphine sulfate $/ 1.2 \mathrm{mg}$ naltrexone $\mathrm{HCl}$ and were prepared by first emptying the content (pellet) of the MSN capsule into a mortar and pestle and then manually crushing the pellet for a minimum of $2 \mathrm{~min}$. For all doses during the dose selection, drug discrimination and treatment phases, crushed contents were transferred to an amber glass vial with a straw for insufflation.

\section{Blinding}

The dose selection, drug discrimination and treatment phases were conducted in a double-blinded manner. To maintain blinding, the study drug was provided in opaque vials with a straw-like tube to assist with drug insufflation. The only individuals with access to the blinding schema were the pharmacy staff responsible for dispensing the study drug, the unblinded compliance staff who audited pharmacy procedures to verify conformity to the protocol and the unblinded statisticians who generated the randomization code. Following completion of the dose selection and drug discrimination phases, the participants' treatment sequences were unblinded and the data were reviewed to assess the appropriate dose selection and/or eligibility for the treatment phase, respectively. For the treatment phase, the blind was not broken until all participants had completed the study and the database was locked. The protocol specified that the blind could be broken only if specific emergency treatment would be dictated by knowing the treatment status of a participant. If such a case arose, the investigator may have determined the identity of the treatment by opening the participant's sealed code break envelope. Individual code breaks by the investigator would have resulted in the withdrawal of the participant from the study; however, none occurred.

\section{PD assessments}

PD assessments were conducted following a training session during each of the dose selection, drug discrimination and treatment phases.

Primary end points were drug liking VAS ("At this moment, my liking for this drug is") and high VAS ("I am feeling high"). Secondary end points included pupillometry measures and the following VAS items: good drug effects ("I can feel good drug effects"), bad drug effects ("I can feel bad drug effects"), any drug effects ("I can feel any drug effect"), feel sick ("I am feeling sick"), nausea ("I am feeling nausea"), sleepy ("I am feeling sleepy") and dizzy ("I am feeling dizzy"). VAS scores were collected at predose (for all PD end points that were not directly relevant to the drug effect, ie, high, feel sick, nausea, sleepy or dizzy) and at $0.5 \mathrm{~h}$, $1 \mathrm{~h}, 1.5 \mathrm{~h}, 2 \mathrm{~h}, 3 \mathrm{~h}, 4 \mathrm{~h}, 6 \mathrm{~h}, 8 \mathrm{~h}, 12 \mathrm{~h}$ and 24 h postdose. Global assessments of overall drug liking VAS ("Overall, my liking for this drug is") and take drug again VAS ("I would take this drug again") were also included as secondary end points but were only administered at $12 \mathrm{~h}$ and $24 \mathrm{~h}$ postdose. Drug liking and overall drug liking VAS were presented on 100-point bipolar scales, in which $0=$ strong disliking, $100=$ strong liking and $50=$ neutral. The drug liking VAS assessed the participant's liking of the drug at the moment the question was asked, whereas the overall drug liking VAS and take drug again VAS assessed global drug effects (ie, the entire drug experience). All other VAS assessed the pharmacological response to the study drugs on a 100-point unipolar scale, where $0=$ definitely not and $100=$ definitely so. VAS results were captured electronically using computerized proprietary software (Scheduled Measurement System; Kendle Early Stage). Pupillometry measurements were taken using the NeurOptics Pupillometer NPI-1 (Neuroptics Inc, USA) in a well-controlled, dimly lit room.

A subject rating scale for nasal effects assessed five categories, including burning, facial pain/pressure, nasal congestion, need to blow nose and runny nose/nasal discharge, using a six-point scale at predose and at $0.5 \mathrm{~h}, 1 \mathrm{~h}, 1.5 \mathrm{~h}$ and $2 \mathrm{~h}$ postdose.

Principal parameters of interest for subjective measures included $\mathrm{E}_{\max }$ and the effects occurring within $2 \mathrm{~h}$ following dosing as assessed by the area under the effect curve $\left(\mathrm{AUE}_{0-2 \mathrm{~h}}\right)$. For pupillometry, the minimum peak effect $\left(\mathrm{E}_{\mathrm{min}}\right)$ was derived.

\section{PK assessments}

Blood samples for analysis of plasma concentrations of morphine, naltrexone and $6 \beta$-naltrexol were drawn at predose and $0.5 \mathrm{~h}, 1 \mathrm{~h}, 1.5 \mathrm{~h}$, $2 \mathrm{~h}, 3 \mathrm{~h}, 4 \mathrm{~h}, 6 \mathrm{~h}, 8 \mathrm{~h}, 12 \mathrm{~h}$ and $24 \mathrm{~h}$ postdose during the treatment phase only. Samples were collected into two $4 \mathrm{~mL}$ K2-EDTA Vacutainer tubes (Becton Dickinson, USA) and centrifuged at $3000 \mathrm{rpm}$ for $10 \mathrm{~min}$ at $4^{\circ} \mathrm{C}$ within $1 \mathrm{~h}$ of sample collection. Plasma was transferred into polypropylene tubes and stored frozen until analysis. The plasma samples were analyzed by CEDRA Corporation (USA) using validated methods. PK parameters were determined using noncompartmental methods and included peak concentration $\left(\mathrm{C}_{\max }\right)$, time to peak concentration $\left(\mathrm{T}_{\max }\right)$, elimination half-life, area under the concentration-time curve (AUC) from time $0 \mathrm{~h}$ to $2 \mathrm{~h}\left(\mathrm{AUC}_{0-2 \mathrm{~h}}\right)$ following dosing and AUC time zero extrapolated to infinity.

\section{Safety assessments}

Spontaneous and timed adverse events (AEs) were documented using the Medical Dictionary for Regulatory Activities Terminology version 12.1. Other safety evaluations included vital signs (blood pressure, heart rate, respiratory rate, oxygen saturation of hemoglobin), clinical laboratory tests (hematology, serum chemistry, serology, urinalysis) and 12-lead electrocardiography.

\section{Statistical analyses}

Power calculations for select analyses were performed given the completion size of 24 participants. The comparison of crushed MSN versus crushed MS for $\mathrm{E}_{\max }$ for drug liking should have a power of $\geq 82 \%$, assuming a mean difference of 15 to 30 points and an SD of the paired differences of 15 to 20 points, based on a paired $t$ test for analysis and a conservative multiple comparison adjustment of $\mathrm{P}=0.0125(0.05 / 4)$. Other end points (ie, $\mathrm{AUE}_{0-2 \mathrm{~h}}$ for drug liking and $\mathrm{E}_{\max }$ and $\mathrm{AUE}_{0-2 \mathrm{~h}}$ for high) have demonstrated larger mean differences in previous abuse liability trials (16) and, thus, the power for these analyses was anticipated to be larger. The planned sample size was considered to be sufficient for both primary end points and the two principal parameters $\left(\mathrm{E}_{\max }\right.$ and $\left.\mathrm{AUE}_{\mathrm{O}-2 \mathrm{~h}}\right)$.

For PD analyses, the evaluable population included all randomized participants who completed all three periods of the treatment phase. PD 


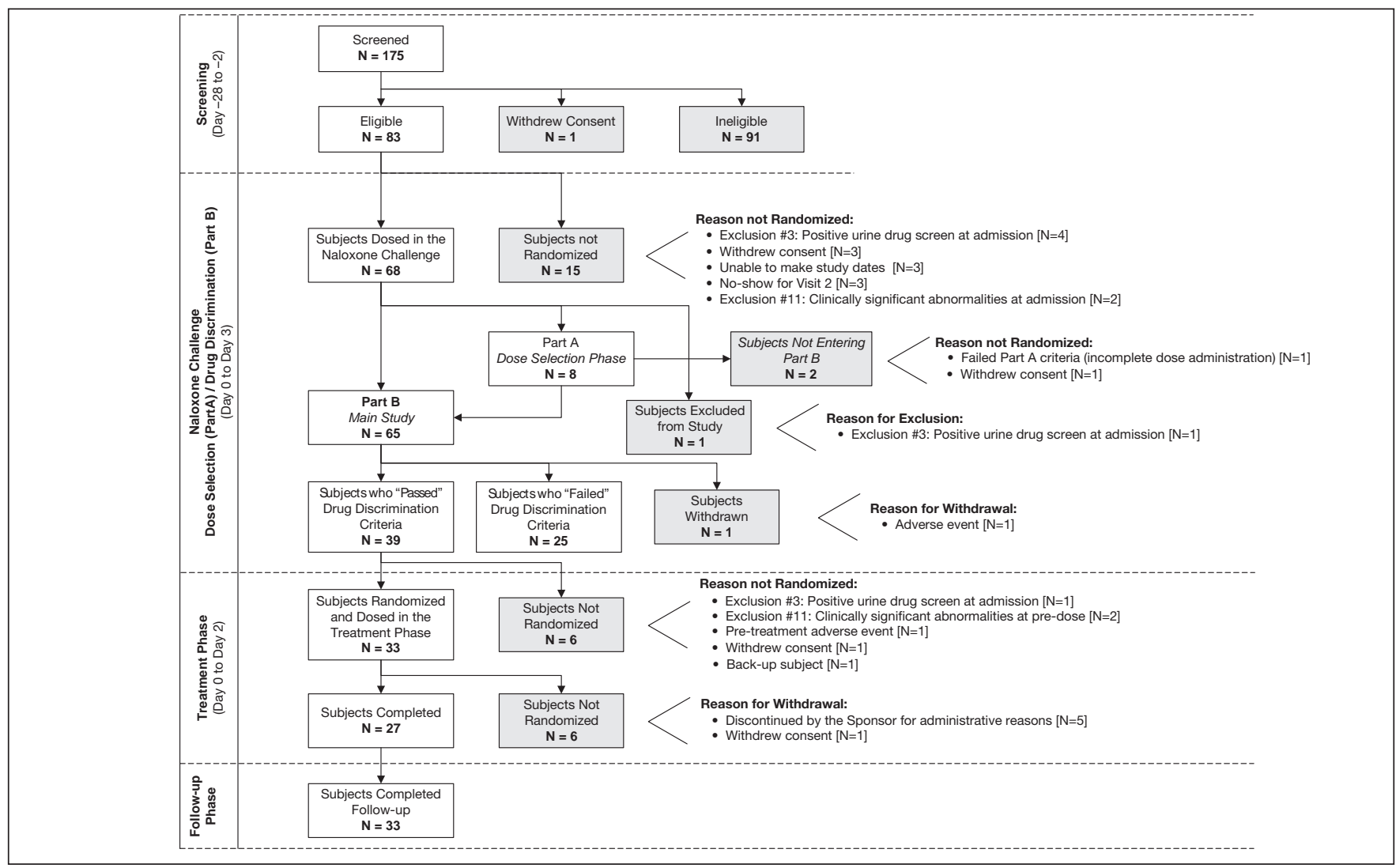

Figure 1) Summary of participant disposition

TABLE 1

\section{Demographics and baseline characteristics}

Summary statistics, $n=33$

Age, years

Mean \pm SD

$35.2 \pm 10.01$

Median (range)

33 (20-53)

Sex

Male

Female

Ethnicity

Hispanic or Latino

Not Hispanic or Latino

29 (88)

Race

White

Black or African American

3 (9)

Asian

$79.18 \pm 8.86$

Weight, $\mathrm{kg}$, mean $\pm \mathrm{SD}$

$25.62 \pm 2.75$

Body mass index, $\mathrm{kg} / \mathrm{m}^{2}$, mean $\pm \mathrm{SD}$

Data presented as $n$ (\%) unless otherwise indicated

primary end points were analyzed using a mixed-effects model (SAS version 9.1 or higher; SAS Institute, Inc, USA) for a crossover study using treatment, period and sequence as fixed effects and subject nested within the sequence as a random effect. All statistical tests were conducted using two-tailed significance criteria. The Benjamini-Hochberg procedure was used to control for type I errors arising from multiple comparisons (19). The percentage reduction in drug liking and high VAS $\mathrm{E}_{\max }$ was calculated for crushed MSN $30 \mathrm{mg}$ using crushed MS $30 \mathrm{mg}$ as the reference and was summarized categorically in $10 \%$ increments.

PK and safety parameters were summarized descriptively for all participants who received $\geq 1$ dose of study drug.

\section{Participants}

\section{RESULTS}

Participant disposition is summarized in Figure 1. Demographics of the participants within the safety population of the treatment phase $(n=33)$ are summarized in Table 1 . In addition to previous recreational drug experience with opioids, the majority of participants had experience with cannabinoids and stimulants (mostly marijuana and cocaine, respectively), whereas fewer participants had experience with hallucinogens, dissociative anaesthetics and/or depressants.

\section{Pharmacodynamic outcomes}

Following the first cohort of four participants in the dose selection phase, MS $30 \mathrm{mg}$ was identified as an appropriate dose that safely produced distinguishable effects on PD measures (drug liking and high VAS) after intranasal administration. This observation was confirmed with a second cohort of four participants. Thus, dose escalation to $60 \mathrm{mg}$ and $90 \mathrm{mg}$ was not warranted, and $30 \mathrm{mg}$ was chosen as the dose for MS and MSN in the drug discrimination and treatment phases.

Validity of the study was evaluated through statistical comparison of $\mathrm{E}_{\max }$ for the primary measures (drug liking and high VAS) between placebo and crushed MS. A main effect of treatment was statistically significant for $\mathrm{E}_{\max }$ on both primary measures $(\mathrm{P}<0.001)$, and contrasts showed that administration of crushed MS $30 \mathrm{mg}$ was associated with statistically significant higher $\mathrm{E}_{\max }$ of drug liking VAS, with least squares mean $\left( \pm \mathrm{SE}\right.$ ) of $87.9 \pm 2.32$ points and $\mathrm{E}_{\max }$ of high VAS at $87.9 \pm 3.07$ points compared with placebo drug liking VAS $50.6 \pm 2.38$ points and high VAS $3.5 \pm 3.01$ points, thereby validating the study.

The mean scores over time of the primary outcomes of drug liking and high VAS are shown in Figures 2A and 2B, respectively. Mean scores for each measure peaked within $1 \mathrm{~h}$ after dosing with intranasally administered crushed MS and then gradually declined over time to near-placebo levels by $6 \mathrm{~h}$ to $8 \mathrm{~h}$ postdose for drug liking VAS and by $12 \mathrm{~h}$ postdose for high VAS. Crushed MSN was associated with lower drug liking and high VAS scores compared with crushed MS at all time points, including the 


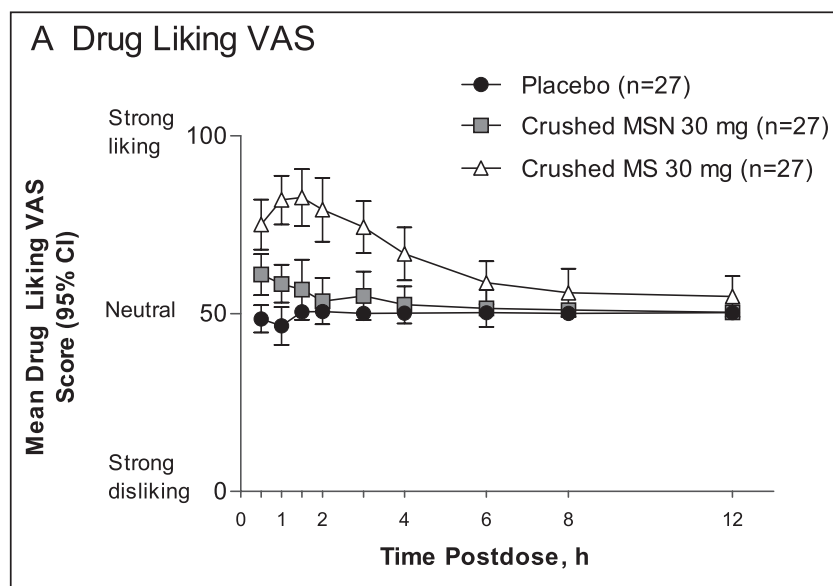

B High VAS

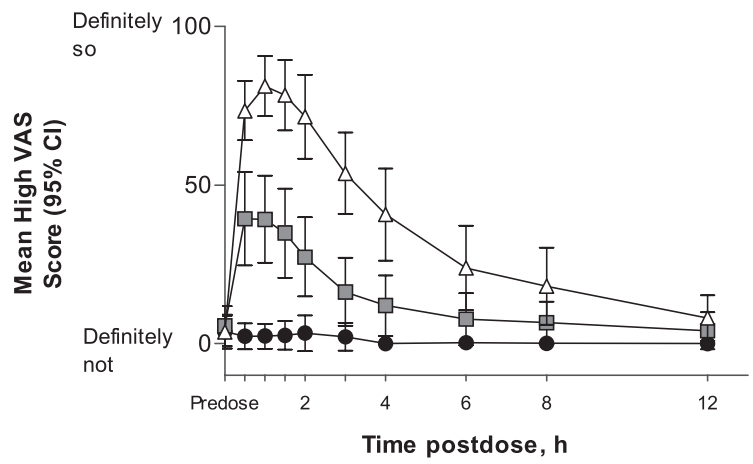

Figure 2) Pharmacodynamic measures over time (evaluable population, $n=27$ ). MS Morphine sulfate; MSN Morphine sulfate surrounding an inner core of sequestered naltrexone; VAS Visual analogue scale

mean peaks, which were observed within $1 \mathrm{~h}$ postdose, but was associated with higher scores compared with placebo. Both MS and MSN had significantly higher $\mathrm{E}_{\max }$ values compared with placebo; however, $\mathrm{E}_{\max }$ on drug liking and high VAS was significantly lower for crushed MSN compared with crushed MS (Table 2). This pattern also held true for the $\mathrm{AUE}_{0-2 \mathrm{~h}}$ (Table 2). Relative to crushed MS, MSN was associated with a $20 \%$ mean reduction in $\mathrm{E}_{\max }$ for drug liking VAS, and 21 (78\%) participants showed at least some reduction. Per cent reduction for high VAS showed a $39 \%$ mean reduction in $\mathrm{E}_{\max }$ following intranasal administration of crushed MSN relative to MS, and 20 (74\%) participants showed at least some reduction. Four participants (15\%) showed a complete $(100 \%)$ reduction in feeling high (ie, a score of 0 ).

Mean VAS scores $\left(\mathrm{E}_{\max }\right)$ of the secondary measures are summarized in Table 3. Crushed MSN was associated with significantly lower $\mathrm{E}_{\max }$ on all secondary positive subjective effects, including good drug effects, and the global drug assessments of overall drug liking and take drug again compared with crushed MS (Table 3), but the scores were significantly higher compared with placebo. Crushed MSN was associated with significantly lower $\mathrm{E}_{\max }$ on the end points, any drug effects and sleepy compared with crushed MS, but scores were significantly higher compared with placebo. All other effects (bad drug effects, feeling sick, nausea and dizzy VAS) were not significantly different between MSN and MS or MSN and placebo. Crushed MS was associated with significantly higher $\mathrm{E}_{\max }$ on bad drug effects and dizzy compared with placebo (Table 3).

Derived parameters of each subscale in the subject rating scale for nasal effects were low across all treatments. Pairwise comparisons indicated that both crushed MS and crushed MSN had $\mathrm{E}_{\max }$ and $\mathrm{AUE}_{0-2 \mathrm{~h}}$ values that were statistically indistinguishable for all nasal effects. MS had significantly higher $\mathrm{E}_{\max }$ and $\mathrm{AUE}_{0-2 \mathrm{~h}}$ compared with placebo for burning, nasal congestion, runny nose/nasal discharge and need to
TABLE 2

Summary of primary end points: Least squares mean visual analogue scale scores $(95 \% \mathrm{Cl})$, evaluable population $(n=27)$

\begin{tabular}{|c|c|c|c|c|}
\hline \multirow[b]{2}{*}{ Endpoint } & \multicolumn{3}{|c|}{ Visual analogue scale score $(95 \% \mathrm{Cl})$} & \multirow[b]{2}{*}{$\begin{array}{c}\text { Adjusted } \\
\mathrm{P}^{*}\end{array}$} \\
\hline & Placebo & $\begin{array}{c}\text { Crushed MSN } \\
30 \mathrm{mg}\end{array}$ & $\begin{array}{l}\text { Crushed MS } \\
\quad 30 \mathrm{mg}\end{array}$ & \\
\hline \multicolumn{5}{|l|}{ Drug liking ${ }^{\dagger}$} \\
\hline $\mathrm{E}_{\max }$ & $\begin{array}{c}50.9 \\
(45.3-56.5)\end{array}$ & $\begin{array}{c}69.6 \\
(63.9-75.3)\end{array}$ & $\begin{array}{c}87.6 \\
(81.9-93.2)\end{array}$ & $\begin{array}{l}<0.001^{\S} \\
<0.001^{\Uparrow} \\
<0.001^{\star \star}\end{array}$ \\
\hline $\mathrm{AUE}_{0-2 \mathrm{~h}}$ & $\begin{array}{c}73.1 \\
(64.5-81.6)\end{array}$ & $\begin{array}{c}86.3 \\
(77.7-94.9)\end{array}$ & $\begin{array}{c}120.6 \\
(112.2-129.0)\end{array}$ & $\begin{array}{c}<0.001^{\S} \\
0.022^{\Uparrow} \\
<0.001^{\star *}\end{array}$ \\
\hline \multicolumn{5}{|l|}{ High $^{\ddagger}$} \\
\hline $\mathrm{E}_{\max }$ & $\begin{array}{c}3.7 \\
(-6.0-13.3)\end{array}$ & $\begin{array}{c}55.2 \\
(45.5-64.9)\end{array}$ & $\begin{array}{c}86.6 \\
(77.0-96.3)\end{array}$ & $\begin{array}{l}<0.001^{\S} \\
<0.001^{\Uparrow} \\
<0.001^{\star \star}\end{array}$ \\
\hline $\mathrm{AUE}_{0-2 \mathrm{~h}}$ & $\begin{array}{c}6.1 \\
(-10.1-22.4)\end{array}$ & $\begin{array}{c}66.7 \\
(50.5-82.8)\end{array}$ & $\begin{array}{c}132.9 \\
(116.6-149.1)\end{array}$ & $\begin{array}{l}<0.001^{\S} \\
<0.001^{\Uparrow} \\
<0.001^{\star \star}\end{array}$ \\
\hline
\end{tabular}

${ }^{*} P$ values adjusted using the Benjamini-Hochberg method; ${ }^{\dagger}$ Based on visual analogue scale drug liking score in which $0=$ strong disliking, $100=$ strong liking (50 = neutral); ${ }^{\ddagger}$ Based on visual analogue scale high score in which $0=$ definitely not, 100 = definitely so; ${ }^{\S}$ Significant difference between morphine sulfate surrounding an inner core of sequestered naltrexone (MSN) and morphine sulfate (MS); "Significant difference between MSN and placebo; ${ }^{*}$ Significant difference between $M S$ and placebo. $A \cup E_{0-2 h}$ Area under the effect curve from time $0 \mathrm{~h}$ to $2 \mathrm{~h}$; $E_{\max }$ Maximum effect;

blow nose $(\mathrm{P}<0.02)$. For MSN, significantly higher $\mathrm{E}_{\max }$ compared with placebo was observed for burning, runny nose/nasal discharge and need to blow nose $(\mathrm{P}<0.05)$ and significantly higher $\mathrm{AUE}_{0-2 \mathrm{~h}}$ for burning $(\mathrm{P}=0.014)$. No statistically significant effect was observed for any facial pain/pressure among treatments.

Pupil diameter remained consistent throughout the time course of assessment for placebo (Figure 3). Crushed MS was associated with a gradual decrease in mean pupil size up to $2 \mathrm{~h}$ postdose; this decrease was sustained up to $8 \mathrm{~h}$ postdose and returned to near baseline levels at $24 \mathrm{~h}$ postdose. Mean pupil size following administration of crushed MSN also decreased, but the effect was less marked compared with crushed MS (Figure 3$)$. The peak reduction $\left(\mathrm{E}_{\min }\right)$ was significantly less after crushed MSN relative to crushed MS, but greater than that of placebo (Table 3).

\section{Pharmacokinetic outcomes}

Plasma morphine concentration-time profiles (Figure 4) and PK parameters (Table 4) over the $24 \mathrm{~h}$ assessment period were similar for MSN compared with MS when crushed and administered intranasally. Mean plasma morphine concentrations increased sharply and reached $\mathrm{C}_{\max }$ with a median $\mathrm{T}_{\max }$ of $0.57 \mathrm{~h}$ for MSN and $0.6 \mathrm{~h}$ for MS. Median $\mathrm{T}_{\max }$ for naltrexone was similar to that of morphine following MSN administration ( $0.55 \mathrm{~h}$; Figure 5, Table 4). As expected, naltrexone and $6 \beta$-naltrexol were below the limit of quantification for the majority of participants following administration of MS. There were a few values above the limit of quantification for some participants; however, these were likely attributable to variations in the bioanalytical assay because these values were sporadic and not consistent for any one participant following administration of MS.

\section{Safety}

The overall incidence of AEs during the treatment phase was comparable between MSN (77\%) and MS (79\%) when administered intranasally; however, MSN resulted in a lower incidence of euphoric mood compared with MS (39\% versus 59\%, respectively) and lower incidence of dizziness (3\% versus $21 \%$, respectively) (Table 5). AEs occurred at a 
TABLE 3

Summary of secondary endpoints: Least squares mean visual analogue scale maximum score $\left(E_{\max }\right)(95 \% \mathrm{Cl})$, evaluable population $(n=27)$

\begin{tabular}{|c|c|c|c|c|}
\hline \multirow[b]{2}{*}{ End point } & \multicolumn{3}{|c|}{ Visual analogue scale score $\mathrm{E}_{\max }(95 \% \mathrm{Cl})$} & \multirow[b]{2}{*}{$P^{*}$} \\
\hline & Placebo & $\begin{array}{c}\text { Crushed MSN } \\
30 \mathrm{mg}\end{array}$ & $\begin{array}{c}\text { Crushed MS } \\
30 \mathrm{mg}\end{array}$ & \\
\hline \multicolumn{5}{|l|}{ Positive effects } \\
\hline Good drug effects & $\begin{array}{c}4.4 \\
(-5.8-14.6)\end{array}$ & $\begin{array}{c}58.3 \\
(48.1-68.4)\end{array}$ & $\begin{array}{c}88.1 \\
(77.9-98.3)\end{array}$ & $\begin{array}{l}<0.001^{\dagger} \\
<0.001^{\ddagger} \\
<0.001^{\S}\end{array}$ \\
\hline Overall drug liking & $\begin{array}{c}50.9 \\
(43.5-58.3)\end{array}$ & $\begin{array}{c}60.8 \\
(53.4-68.3)\end{array}$ & $\begin{array}{c}83.8 \\
(76.5-91.1)\end{array}$ & $\begin{array}{l}<0.001^{\dagger} \\
0.043^{\ddagger} \\
<0.001^{\S}\end{array}$ \\
\hline Take drug again & $\begin{array}{c}42.2 \\
(33.0-51.4)\end{array}$ & $\begin{array}{c}60.6 \\
(51.4-69.9)\end{array}$ & $\begin{array}{c}84.9 \\
(75.7-94.2)\end{array}$ & $\begin{array}{l}<0.001^{\dagger} \\
0.002^{\ddagger} \\
<0.001^{\S}\end{array}$ \\
\hline \multicolumn{5}{|l|}{ Negative effects } \\
\hline Bad drug effects & $\begin{array}{c}4.1 \\
(-5.3-13.5)\end{array}$ & $\begin{array}{c}14.8 \\
(5.6-23.9)\end{array}$ & $\begin{array}{c}20.0 \\
(10.8-29.2)\end{array}$ & $\begin{array}{c}\text { NS } \\
\text { NS } \\
0.012^{\S}\end{array}$ \\
\hline Feeling sick & $\begin{array}{c}-0.2^{\pi} \\
(-5.2-4.8)\end{array}$ & $\begin{array}{c}4.3 \\
(-0.4-8.9)\end{array}$ & $\begin{array}{c}5.8 \\
(1.0-10.6)\end{array}$ & $\begin{array}{l}\text { NS } \\
\text { NS } \\
\text { NS }\end{array}$ \\
\hline Nausea & $\begin{array}{c}3.6 \\
(-2.8-10.0)\end{array}$ & $\begin{array}{c}5.1 \\
(-1.4-11.6)\end{array}$ & $\begin{array}{c}8.8 \\
(2.3-15.4)\end{array}$ & $\begin{array}{l}\text { NS } \\
\text { NS } \\
\text { NS }\end{array}$ \\
\hline \multicolumn{5}{|l|}{ Other } \\
\hline Any drug effects & $\begin{array}{c}3.6 \\
(-7.3-14.4)\end{array}$ & $\begin{array}{c}58.7 \\
(47.8-69.5)\end{array}$ & $\begin{array}{c}91.2 \\
(80.4-102.0)\end{array}$ & $\begin{array}{l}<0.001^{\dagger} \\
<0.001^{\ddagger} \\
<0.001^{\S}\end{array}$ \\
\hline Dizzy & $\begin{array}{c}3.1 \\
(-5.8-11.9)\end{array}$ & $\begin{array}{c}8.6 \\
(-0.1-17.3)\end{array}$ & $\begin{array}{c}17.9 \\
(9.1-26.7)\end{array}$ & $\begin{array}{c}\text { NS } \\
\text { NS } \\
0.016^{\ddagger}\end{array}$ \\
\hline Sleepy & $\begin{array}{c}20.8 \\
(7.7-33.9)\end{array}$ & $\begin{array}{c}41.1 \\
(27.6-54.6)\end{array}$ & $\begin{array}{c}65.7 \\
(52.1-79.3)\end{array}$ & $\begin{array}{c}0.008^{\dagger} \\
0.022^{\ddagger} \\
<0.001^{\S}\end{array}$ \\
\hline Objective effects & & & & \\
\hline $\begin{array}{r}\text { Pupillometry } \\
\left(E_{\min }, 95 \% \mathrm{Cl}\right)\end{array}$ & $\begin{array}{c}4.5 \\
(4.3-4.7)\end{array}$ & $\begin{array}{c}3.8 \\
(3.6-4.0)\end{array}$ & $\begin{array}{c}3.3 \\
(3.1-3.5)\end{array}$ & $\begin{array}{c}0.002^{\dagger} \\
<0.001^{\ddagger} \\
<0.001^{\S}\end{array}$ \\
\hline
\end{tabular}

*A linear mixed model was used which included baseline (where applicable), treatment, period, and sequence as the fixed effects, and subject nested within sequence as the random effect. ${ }^{\dagger}$ Significant difference between MSN versus MS; ${ }^{\ddagger}$ Significant difference between MSN versus placebo; ${ }^{\S}$ Significant difference between MS versus placebo; " $A$ negative value resulted from the covariance structure specified in the PROC MIXED statement model and because $E_{\text {max }}$ had very little variation for this PD endpoint. MS Morphine sulfate; MSN Morphine sulfate surrounding an inner core of sequestered naltrexone; NS Not significant

much lower incidence following administration of placebo (10\%). The most common AEs reported were consistent with known morphine effects (ie, euphoric mood, somnolence, headache and dizziness) (Table 5). Most AEs were mild and were considered to be related to study drug. No participants were discontinued because of AEs and there were no deaths or other serious AEs. Treatment-emergent changes in vital signs were mild, transient and not clinically relevant. No electrocardiographic abnormalities were clinically relevant. Three postdose cardiac-related AEs were detected via cardiac telemetry following placebo administration in the dose discrimination phase: in two participants it was deemed to be unrelated to study drug but, for their safety, the participants were discontinued before treatment phase. The other

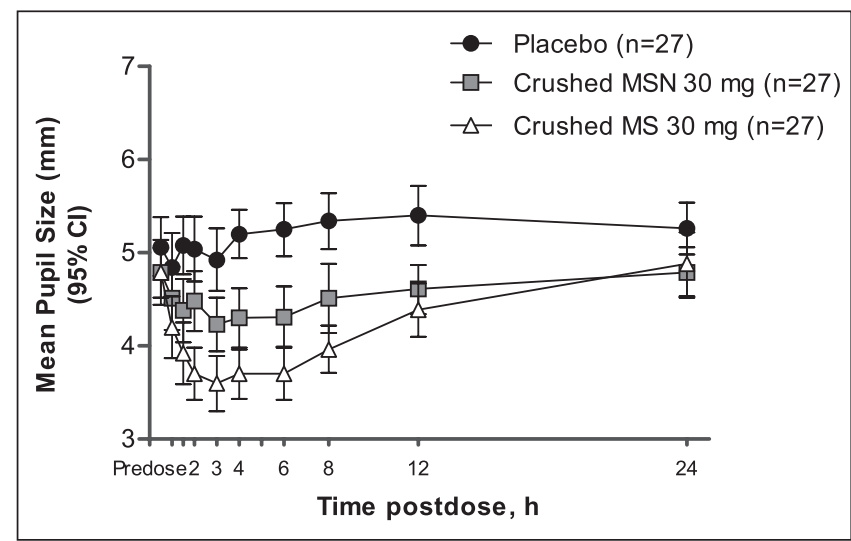

Figure 3) Pupillometry over time (evaluable population, $n=27)$. MS Morphine sulfate; MSN Morphine sulfate surrounding an inner core of sequestered naltrexone

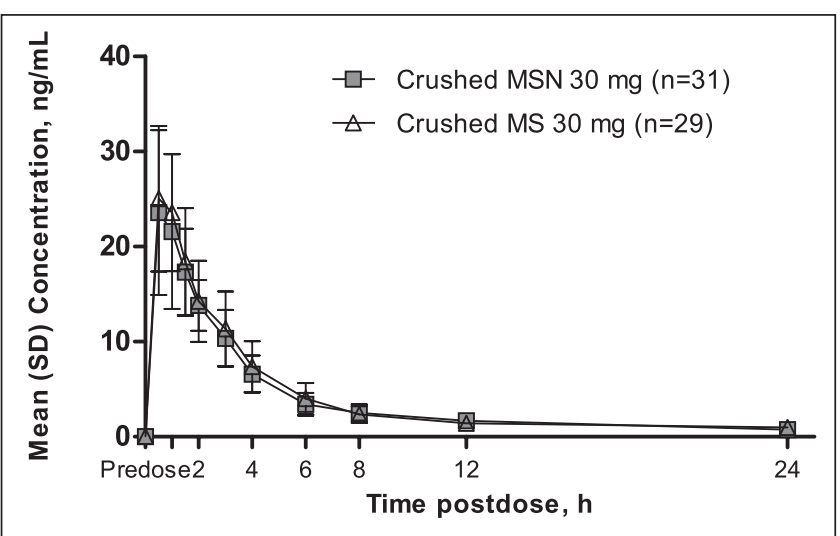

Figure 4) Mean \pm SD plasma concentration-time profiles for morphine in crushed morphine sulfate (MS) and crushed morphine sulfate surrounding an inner core of sequestered naltrexone (MSN).

participant was considered safe to proceed in the study because the $\mathrm{AE}$ was mild in intensity and related to study drug. Two participants had clinically significant findings on their urinalysis panels at follow-up; both were assessed as not related to study drug.

\section{DISCUSSION}

Intranasal administration of crushed MS resulted in significantly higher peak scores on all positive subjective measures compared with placebo, confirming study validity and, to our knowledge, demonstrating for the first time the positive subjective effects of morphine following intranasal administration. MSN had significantly higher ratings compared with placebo on all positive subjective measures; however, MSN had significantly lower scores on all positive subjective measures compared with the active control MS. Intranasal administration of crushed MSN resulted in significantly lower peak scores of drug liking and high. Furthermore, the significantly lower scores for MSN compared with MS were consistently observed across global measures of overall drug liking and take drug again. These retrospective ratings (administered at $12 \mathrm{~h}$ and $24 \mathrm{~h}$ postdose) have the advantage of assessing the entire drug experience when much of the drug's effects have waned and, thus, may predict how probable it is that MSN will be less attractive for misuse and abuse in the future (20). No significant differences were reported on negative subjective effects (bad drug effects, feeling sick or nausea) between MSN and MS. Differences between crushed MSN and MS were approximately 18 points for $\mathrm{E}_{\max }$ on the drug liking VAS (bipolar) and 30 points for $\mathrm{E}_{\max }$ on the high VAS (unipolar). The clinical significance of these findings is supported by recent data that suggest a minimum of an $8 \mathrm{~mm}$ to $10 \mathrm{~mm}$ change in 
TABLE 4

Summary of pharmacokinetic parameters

\begin{tabular}{|c|c|c|c|c|}
\hline \multirow[b]{2}{*}{ Parameter } & \multirow{2}{*}{$\begin{array}{c}\begin{array}{c}\text { Crushed MS } \\
30 \mathrm{mg}(\mathrm{n}=29)\end{array} \\
\text { Morphine }\end{array}$} & \multicolumn{3}{|c|}{ Crushed MSN $30 \mathrm{mg}(\mathrm{n}=31)$} \\
\hline & & Morphine & Naltrexone & $6 \beta$-naltrexol \\
\hline $\mathrm{C}_{\max }, \mathrm{ng} / \mathrm{mL}$ & $\begin{array}{c}27.7 \pm 6.79 \\
(25)\end{array}$ & $\begin{array}{c}27.3 \pm 8.68 \\
(31)\end{array}$ & $\begin{array}{c}1497 \pm 403.2 \\
(29)\end{array}$ & $\begin{array}{c}1106 \pm 386.2 \\
(41)\end{array}$ \\
\hline $\begin{array}{l}\mathrm{T}_{\text {max }}, \mathrm{h}, \\
\text { median (range) }\end{array}$ & $\begin{array}{c}0.6 \\
(0.6-3.0)\end{array}$ & $\begin{array}{c}0.57 \\
(0.5-3.1)\end{array}$ & $\begin{array}{c}0.55 \\
(0.5-1.1)\end{array}$ & $\begin{array}{c}1.53 \\
(0.6-3.1)\end{array}$ \\
\hline $\mathrm{AUC}_{0-2 \mathrm{~h}}, \mathrm{~h} \cdot \mathrm{ng} / \mathrm{mL}$ & $\begin{array}{c}36.7 \pm 8.13 \\
\quad(23)\end{array}$ & $\begin{array}{c}34.4 \pm 7.62 \\
(22)\end{array}$ & $\begin{array}{c}1776 \pm 441.0 \\
(26)\end{array}$ & $\begin{array}{c}1358 \pm 508.7 \\
(42)\end{array}$ \\
\hline$A \cup C_{\text {inf }}, h \cdot n g / m L$ & $\begin{array}{c}110.2 \pm 27.8 \\
(25)\end{array}$ & $\begin{array}{c}103.1 \pm 22.6 \\
(24)\end{array}$ & $\begin{array}{c}3335 \pm 847.9 \\
(27)\end{array}$ & $\begin{array}{c}14,345 \pm 4323 \\
(35)\end{array}$ \\
\hline$t_{1 / 2}, h$ & $\begin{array}{c}9.30 \pm 10.30 \\
(72) \\
\end{array}$ & $\begin{array}{c}8.76 \pm 4.17 \\
(57) \\
\end{array}$ & $\begin{array}{c}2.58 \pm 0.99 \\
(32) \\
\end{array}$ & $\begin{array}{c}13.19 \pm 3.06 \\
(25) \\
\end{array}$ \\
\hline
\end{tabular}

Data presented as mean $\pm S D$ (coefficient of variation) unless otherwise indicated. $\mathrm{AUC}_{0-2} \mathrm{~h}$ Area under the concentration-time curve from time $O h$ to $2 h$ following dosing; $A \cup C_{\text {inf }}$ Area under the plasma concentrationtime curve extrapolated to infinity; $C_{\max }$ Maximum drug concentration; MS Morphine sulfate; MSN Morphine sulfate surrounding an inner core of sequestered naltrexone; $t_{1 / 2}$ Elimination half-life; $T_{\max }$ Time to maximum drug concentration

score on a unipolar $100 \mathrm{~mm}$ scale represents a clinically meaningful difference (21)

The objective pupillometry measurements indicated that naltrexone significantly reduced the pupillary constriction induced by morphine, which is consistent with the results observed for the subjective measures. Negative subjective effects were minimal for both active treatments, which is consistent with previous abuse liability studies of morphine $(13,16)$. Subject-rated nasal effects were low for all treatments. Crushed MS and crushed MSN were associated with greater negative intranasal effects, such as burning or runny nose, relative to placebo. Differences between MS and MSN were not expected on nasal effects because the primary mechanism by which MSN is intended to deter abuse is via antagonist blockade upon crushing, and not through aversive agents such as nasal irritants or other excipients.

In the present study, intranasal administration of crushed MS and crushed MSN resulted in similar PK profiles of morphine in plasma. Therefore, the statistically significant reductions in subjective and objective responses observed following intranasal administration of crushed MSN relative to crushed MS are unlikely to be attributable to differences in exposure to morphine but rather may be related to the antagonistic action of naltrexone released when MSN is crushed. Indeed, naltrexone was observed to be readily bioavailable following intranasal administration of crushed MSN. The relatively high concentration of naltrexone observed is important in antagonizing the positive subjective effects of intranasally administered morphine that contribute to its abuse $(13,16)$.

Intranasal administration of MSN and MS was generally well tolerated by nondependent recreational opioid users, and the most common AEs (euphoric mood, somnolence, headache and dizziness) were typical of morphine $(11,22)$. Intranasal administration of crushed MSN with naltrexone resulted in a somewhat lower incidence of euphoric mood and dizziness as well as fewer opiate-type gastrointestinal effects. The lower incidence of opioid-type treatment-emergent AEs following administration of crushed MSN compared with crushed MS was generally consistent with observations on the subjective and objective measures.

The present study had several limitations. Although statistically powered, the study population is limited by a relatively small sample size. As recommended by the guidelines for abuse liability studies, the population in the present study included healthy, nondependent recreational opioid users; some argue that this may not be reflective of patients with chronic pain for whom MSN is intended, although many deem that these same methods have predictive applicability both to recreational drug users and patients (20). Only one dose of the drug

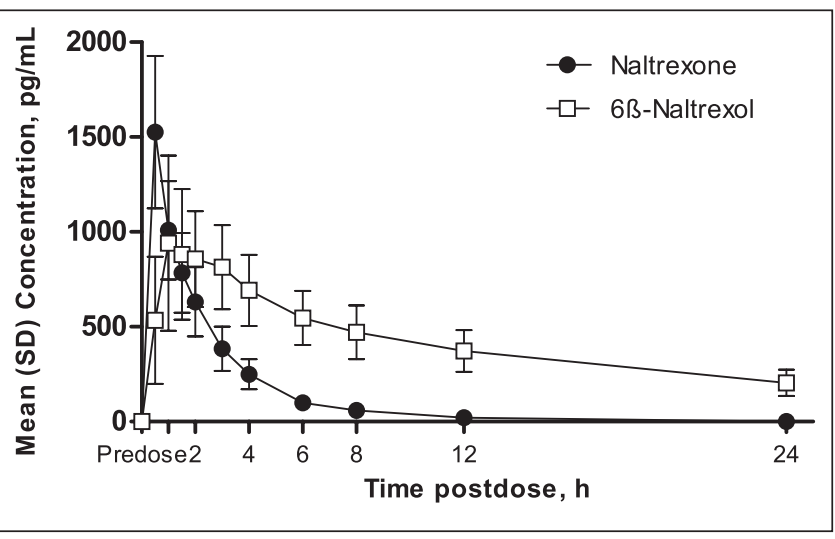

Figure 5) Mean \pm SD plasma concentration-time profiles for naltrexone and $6 \beta$-naltrexol in crushed morphine sulfate surrounding an inner core of sequestered naltrexone

\section{TABLE 5}

Most common adverse events ( $\geq 5 \%$ with any treatment) during the treatment phase (safety population)*

\begin{tabular}{lccc}
\hline & $\begin{array}{c}\text { Placebo } \\
(\mathbf{n}=\mathbf{3 1})\end{array}$ & $\begin{array}{c}\text { Crushed MSN } \\
(\mathbf{n}=\mathbf{3 1})\end{array}$ & $\begin{array}{c}\text { Crushed MS } \\
(\mathbf{n}=\mathbf{2 9})\end{array}$ \\
\hline Euphoric mood & 0 & $12(39)$ & $17(59)$ \\
Somnolence & 0 & $7(23)$ & $7(24)$ \\
Headache & $1(3)$ & $7(23)$ & $6(21)$ \\
Dizziness & 0 & $1(3)$ & $6(21)$ \\
Nausea & 0 & $1(3)$ & $2(7)$ \\
Dysgeusia & 0 & 0 & $2(7)$ \\
Feeling of relaxation & 0 & $1(3)$ & $2(7)$ \\
Nasal discomfort & 0 & $1(3)$ & $2(7)$ \\
Feeling hot & 0 & $2(6)$ & $1(3)$
\end{tabular}

Data presented as $n$ (\%). *Includes all randomized participants who received $\geq 1$ dose of study drug in the treatment phase. MS Morphine sulfate; MSN Morphine sulfate surrounding an inner core of sequestered naltrexone

was evaluated, which is a dose that is relevant to the population of recreational drug users sampled and may not reflect the doses of morphine that may be used or abused in novice or dependent users. The study was limited to nondependent participants and, therefore, the potential of naltrexone to cause withdrawal, an effect that may potentially serve as an additional deterrent to tampering and abuse in individuals who are opioid-dependent, was not evaluated.

\section{CONCLUSION}

When crushed and administered intranasally, MSN was associated with consistent reduction across all positive subjective measures studied compared with MS. As with previous findings, the naltrexone in MSN reduced the positive/euphorigenic effects of morphine as opposed to introducing negative or aversive effects when administered to a population of nondependent recreational opioid users. Although the PD end points used in the present study are well accepted as indicators of abuse potential, long-term epidemiological studies with extensive postmarketing surveillance are required to establish whether MSN will be less desirable for misuse and abuse.

\section{SUMMARY}

The subjective and physiological effects of MSN capsules were compared with MS and placebo when crushed and administered intranasally. Both MS and MSN showed significantly higher PD values than placebo. MSN showed significantly lower scores for drug liking and high VAS (scales ranging from 0 to 100) than MS. MSN also showed significantly lower scores for good drug effects, overall drug liking and 
take drug again VAS than MS. Peak minimum pupil diameter was significantly larger for MSN than MS. Plasma morphine profiles and PK parameters were similar after taking MSN and MS.

ACKNOWLEDGEMENTS: Medical writing support was provided by Vardit Dror PhD of UBC Scientific Solutions, and was funded by Pfizer Inc.

FINANCIAL SUPPORT: This study was sponsored by King Pharmaceuticals, Inc, which was acquired by Pfizer Inc in March 2011. King Pharmaceuticals, Inc was responsible for the protocol and overall development of the study.

CONFLICT OF INTEREST DISCLOSURE: Beatrice Setnik and Veeraindar Goli are employees of Pfizer Inc. Naama Levy-Cooperman, Catherine Mills, Megan Shram, and Ira Smith are employees of INC Research (formerly Kendle Early Stage). The study was conducted at Kendle Early Stage, Toronto, Ontario.

\section{REFERENCES}

1. Paulozzi LJ, Jones CM, Mack KA, Rudd RA. Vital signs: Overdoses of prescription opioid pain relievers - United States, 1999-2008. MMWR Morb Mortal Wkly Rep 2011;60:1487-92.

2. Von Korff M, Kolodny A, Deyo RA, Chou R. Long-term opioid therapy reconsidered. Ann Intern Med 2011;155:325-8.

3. National Survey on Drug Use and Health: Results from the 2010 National Survey on Drug Use and Health: Summary of National Findings. <http://oas.samhsa.gov/NSDUH/2k10NSDUH/2k10Results. $\mathrm{htm}>$ (Accessed December 16, 2011).

4. Hays LR. A profile of OxyContin addiction. J Addict Dis 2004;23:1-9.

5. Katz N, Dart RC, Bailey E, Trudeau J, Osgood E, Paillard F. Tampering with prescription opioids: Nature and extent of the problem, health consequences, and solutions. Am J Drug Alcohol Abuse 2011;37:205-17

6. Butler SF, Budman SH, Licari A, et al. National addictions vigilance intervention and prevention program (NAVIPPRO): A real-time, product-specific, public health surveillance system for monitoring prescription drug abuse. Pharmacoepidemiol Drug Saf 2008;17:1142-54.

7. Calcaterra S, Glanz J, Binswanger IA. National trends in pharmaceutical opioid related overdose deaths compared to other substance related overdose deaths: 1999-2009. Drug Alcohol Depend 2013 [Epub online ahead of print].

8. Substance Abuse and Mental Health Services Administration. The DAWN report. June 18. Trends in emergency department visits involving nonmedical use of narcotic pain relievers. < www.samhsa.gov/data/2k10/ DAWN016/OpioidEDHTML.pdf> (Accessed March 4, 2013).

9. Hamed E, Moe D. Development of tamper deterrent formulations: State of the pharmaceutical industry. Curr Drug Abuse Rev 2010;3:139-46.

10. Raffa RB, Pergolizzi JV, Jr. Opioid formulations designed to resist/ deter abuse. Drugs 2010;70:1657-75.
11. Katz N, Hale M, Morris D, Stauffer J. Morphine sulfate and naltrexone hydrochloride extended release capsules in patients with chronic osteoarthritis pain. Postgrad Med 2010;122:112-28.

12. Webster LR, Brewer R, Wang C, et al. Long-term safety and efficacy of morphine sulfate and naltrexone hydrochloride extended release capsules, a novel formulation containing morphine and sequestered naltrexone, in patients with chronic, moderate to severe pain. J Pain Symptom Manage 2010;40:734-46.

13. Stauffer J, Setnik B, Sokolowska M, Romach M, Johnson F, Sellers E. Subjective effects and safety of whole and tampered morphine sulfate and naltrexone hydrochloride (ALO-01) extended-release capsules versus morphine solution and placebo in experienced non-dependent opioid users: A randomized, double-blind, placebo-controlled, crossover study. Clin Drug Investig 2009;29:777-90.

14. Johnson FK, Stark JG, Bieberdorf FA, Stauffer J. Relative oral bioavailability of morphine and naltrexone derived from crushed morphine sulfate and naltrexone hydrochloride extended-release capsules versus intact product and versus naltrexone solution: A single-dose, randomized-sequence, open-label, three-way crossover trial in healthy volunteers. Clin Ther 2010;32:1149-64.

15. FDA: Division of Anesthesia and Addiction Products tOoRP, the Office of Surveillance and Epidemiology, the Office of Biostatistics, and the Controlled Substance Staff in the Center for Drug Evaluation and Research (CDER). Draft Guidance for Industry Abuse Deterrent Opioids - Evaluation and Labeling. FDA Document Identifier UCM334785 2013.

16. Webster LR, Johnson FK, Stauffer J, Setnik B, Ciric S. Impact of intravenous naltrexone on intravenous morphine-induced high, drug liking, and euphoric effects in experienced, nondependent male opioid users. Drugs R D 2011;11:259-75.

17. Setnik B, Roland CL, Cleveland J, Goli V, Sommerville K, Webster L. Assessing the abuse potential of crushed Embeda ${ }^{\circledR}$ compared to crushed morphine sulfate controlled release tablets and placebo in non-dependent, recreational opioid users following oral administration. Pain Med 2013 June 7 [Epub online ahead of print].

18. American Psychiatric Association. Diagnostic and Statistical Manual of Mental Disorders, 4th edn, Text Revision. 2000. doi:10.1176/appi.books. 9780890423349 .

19. Benjamini $\mathrm{YO}$, Hochberg $\mathrm{YO}$. Controlling the false discovery rate: A practical and powerful approach to multiple testing. J Royal Stat Soc Series B Methodological 1995;57:289-300.

20. Griffiths RR, Bigelow GE, Ator NA. Principles of initial experimental drug abuse liability assessment in humans. Drug Alcohol Depend 2003;70:S41-54.

21. Eaton TA, Comer SD, Revicki DA, et al. Determining the clinically important difference in visual analog scale scores in abuse liability studies evaluating novel opioid formulations. Qual Life Res 2012;21:975-81.

22. Katz N, Sun S, Johnson F, Stauffer J. ALO-01 (morphine sulfate and naltrexone hydrochloride) extended-release capsules in the treatment of chronic pain of osteoarthritis of the hip or knee: Pharmacokinetics, efficacy, and safety. J Pain 2010;11:303-11. 


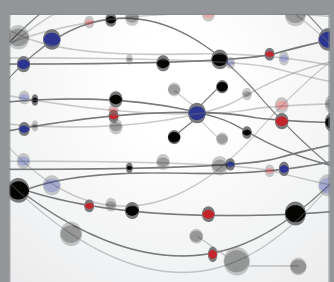

The Scientific World Journal
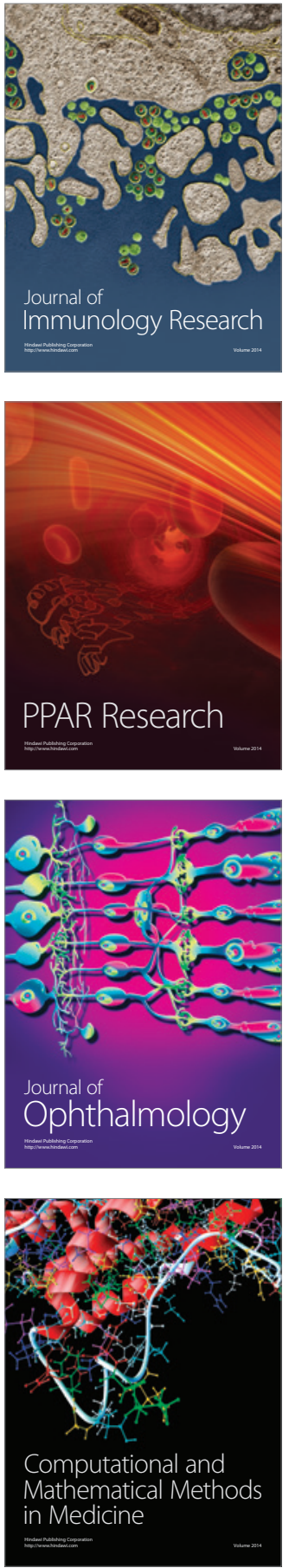

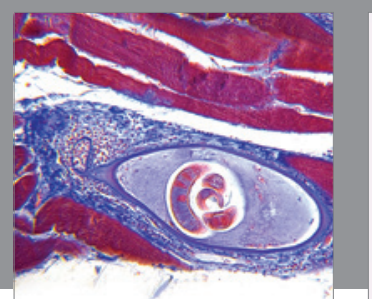

Gastroenterology Research and Practice

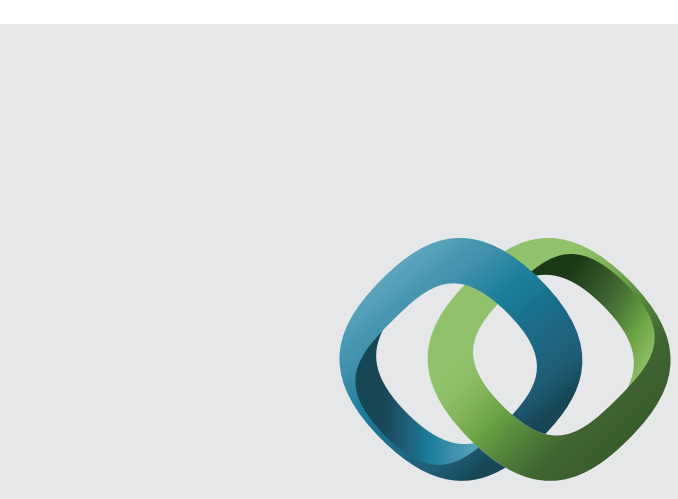

\section{Hindawi}

Submit your manuscripts at

http://www.hindawi.com
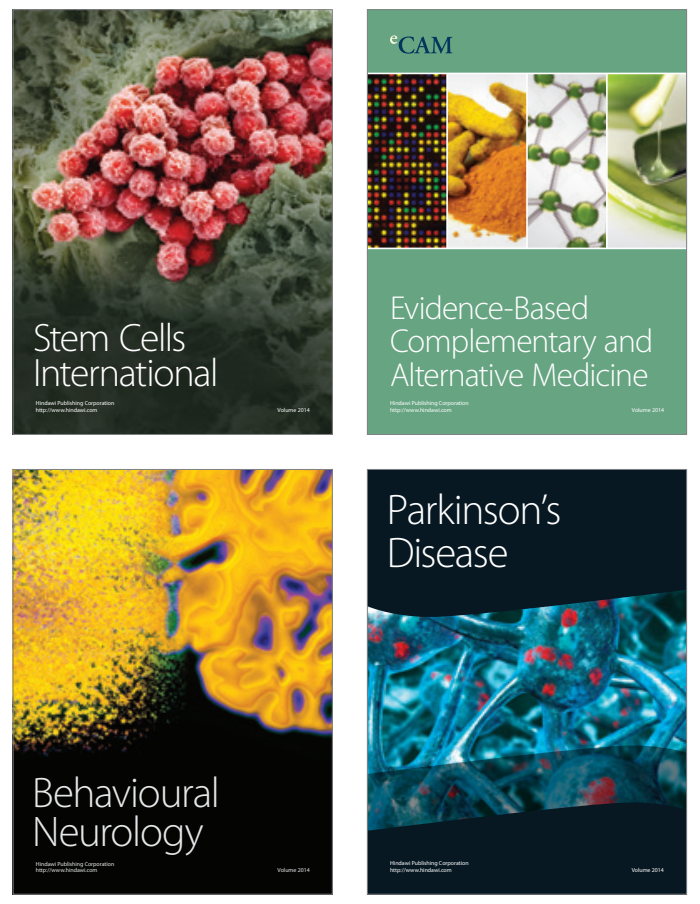
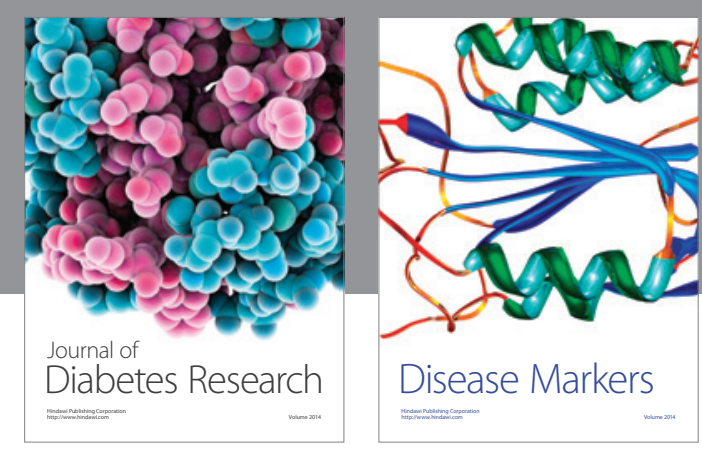

Disease Markers
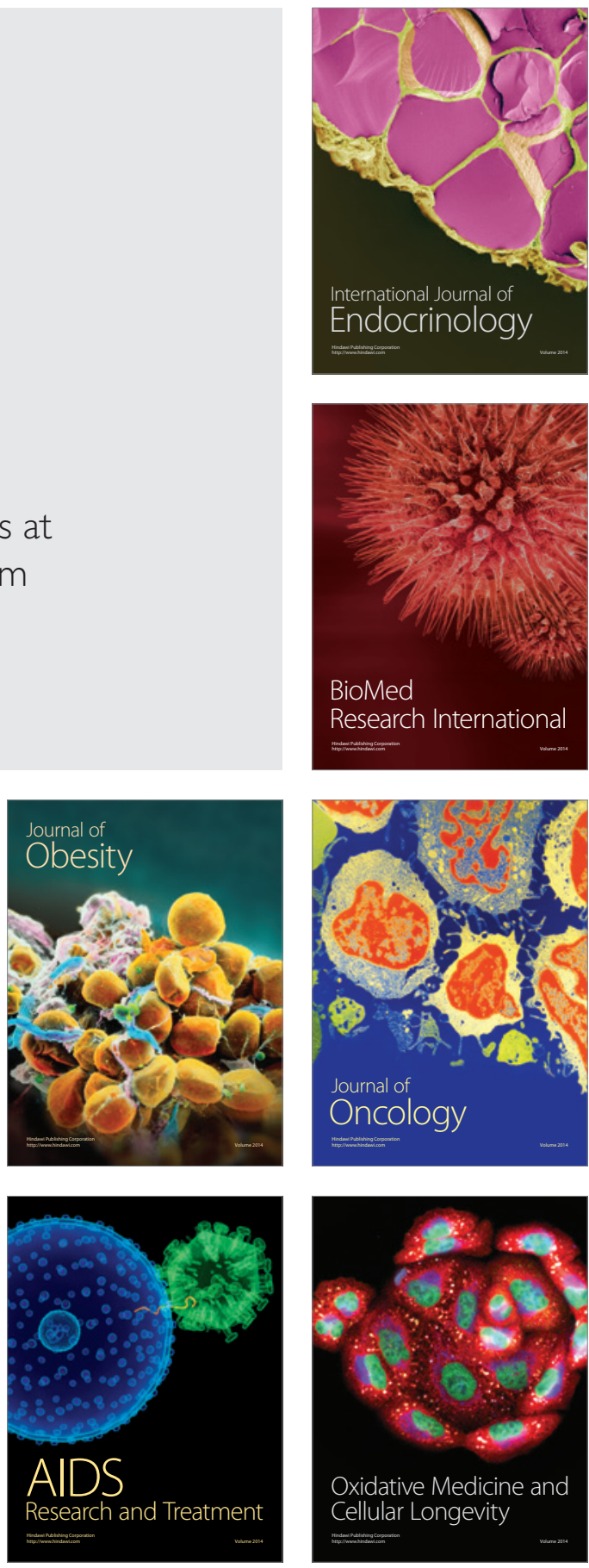